\title{
DUAS PRAÇAS, QUATRO NOMES: CONSIDERAÇÕES ACERCA DA NOMEAÇÃO ESPONTÂNEA EM PIRACANJUBA (GO)
}

\begin{abstract}
Priscila Alves Costa Gomes Geraes Mestranda em Estudos da Linguagem pela Universidade Federal de Goiás (UFG/Regional Catalão)

priscilaalvescosta@hotmail.com

Kênia Mara de Freitas Siqueira

Doutora em Letras e Linguística pela Universidade Federal de Goiás (UFG) Professora da Universidade Estadual de Goiás (UEG) e do Programa de Mestrado em Estudos da Linguagem (PPGEL/RC/UFG) keniamaraueg@gmail.com
\end{abstract}

\section{RESUMO}

O objetivo deste estudo é reconhecer alguns traços da história e da cultura piracanjubense que concorreram, de alguma forma, para, ao lado dos nomes oficiais, fazer surgir topônimos espontâneos para designar duas praças do município de Piracanjuba (GO). Este trabalho traz como resultado alguns dados acerca da nomeação espontânea, que se dá paralelamente à nomeação oficial dessas praças, considerando as propostas de estudo toponímico de fazer onomasiológico, para tanto, acolhem-se os trabalhos de Dick (1990, 1992), Siqueira (2014, 2015, 2018), Biderman (1998), Cabrera (2002) entre outros, cujos estudos se atêm à relação entre nomeação, cultura e história para recuperar os elementos que subjazem à motivação toponímica.

Palavras-chave: onomástica, toponímia, cultura, nomeação espontânea.

\section{ABSTRACT}

This study aims at recognizing some traces of history and culture that somehow contributed to the popularization of unofficial and spontaneous names that refer to two of the main squares in the city of Piracanjuba (GO). As a result, this work presents some data concerning the spontaneous nomination that took place nearly simultaneously to the official nomination of these squares, while also considering some toponymical studies on the onomasyological doing. Therefore, this study considers the studies of Dick (1990, 1992), Siqueira (2014, 2015, 2018), Biderman (1998) and Cabrera (2002), among others, whose studies dwell on the relations between nomination, culture and history to recoup the elements that underlay the toponymical motivation.

Keywords: onomastic, toponymy, culture, spontaneous nomination. 


\section{Introdução}

O interesse pelo estudo dos nomes de praças direciona esta pesquisa no sentido de recuperar alguns elementos da história e da cultura que subjazem à motivação das escolhas de nomes espontâneos de praças do município de Piracanjuba (GO). O foco constitui tanto os nomes oficiais como os espontâneos, nomes pelos quais essas praças são mais conhecidas. Estes tendem a ser mais reveladores dos elementos culturais e históricos que motivam a escolha de um nome, em detrimento de tantos outros que a língua oferece como possibilidade de designar um determinado lugar.

Optou-se por estudar os nomes de duas praças da cidade, pois, embora estas possuam seus nomes oficiais, os falantes se referem a elas usando outros designativos. Isso faz com que, em muitas situações, os nomes ditos oficiais não sejam reconhecidos como tais.

Como aporte teórico, convém mencionar os trabalhos de Biderman (1998), Dick (1990, 1992), Siqueira (2015, 2018), Siqueira e David (2014), Dias (2018), Seabra (2006), Cabrera (2002), Pocklington (s/d), Cunha (1986) e Machado (2003). Para uma breve revisão da histórica do município de Piracanjuba, os dados de Pacífico Filho (2016), Boaventura (2007), Teles (1964) e informações fornecidas pelo site do IBGE foram compilados.

A metodologia do estudo reúne procedimentos da pesquisa qualitativa com análise, interpretação e classificação dos nomes colhidos por meio de mapas e das placas fixadas nas praças. A pesquisa direciona-se por um fazer onomasiológico, buscando descrever os designativos e suas relações com elementos linguísticos, culturais, semânticos e históricos. 
Os resultados apresentados revelam algumas peculiaridades acerca dos nomes de lugares que são escolhidos pelo falante por motivações diversas, que podem estar ligadas a fatores que lhes são estranhos do ponto de vista da nomeação oficial ou pelo não reconhecimento do nome em seus vínculos socioculturais.

\section{Os traços socioculturais nas denominações das praças}

A língua reflete os traços socioculturais daqueles que falam essa língua. Esses traços tornam-se bastante evidentes quando se "elege", individual ou coletivamente, um nome para designar um lugar. Pode-se dizer que, como faculdade humana, a língua é também um fato, um elemento da cultura.

Para Biderman (1998), cada indivíduo, ao nomear, pode conceituar os objetos do mundo, categorizando-os de acordo com a sua realidade e seu senso de entendimento de acordo, sobretudo, com sua visão de mundo. Assim, o léxico de uma língua é uma forma de registrar conhecimento do universo, conforme afirma Biderman (1998, p. 92): “A geração do léxico se processou e se processa através de atos sucessivos de cognição da realidade e de categorização da experiência (...)".

Para Biderman (1998, p. 81), “Ao dar nomes aos objetos, o homem os classifica simultaneamente". A nomeação pode ser considerada a primeira etapa do conhecimento humano, pois foi através dela que o homem foi estruturando o mundo. Assim, no processo de nomeação, há uma aproximação ao real, que permite a cognição da realidade e da categorização da experiência. A esse disposto, Biderman (1998) afirma: 
Assim, a nomeação da realidade pode ser considerada como a etapa primeira no percurso científico do espírito humano de conhecimento do universo. Ao identificar semelhanças e, inversamente, discriminar os traços distintivos que individualizam esses referentes em entidades distintas, o homem, foi estruturando o mundo que o cerca, rotulando essas entidades discriminadas (BIDERMAN, 1998, p. 91-92).

Segundo Siqueira (2018), para realizar um estudo toponímico é utilizado o método onomasiológico, pois este se direciona ao reconhecimento de inúmeras características que compõem uma palavra-sígnica em função de denominação. Em outras palavras, "possibilita reconhecer o que subjaz ao signo linguístico alçado a designativo de lugar por mecanismos intelectuais e em termos da motivação que permeia a escolha de um signo específico e não dos outros mais" (SIQUEIRA, 2018, p. 69).

\subsection{Onomástica}

A Onomástica procura recuperar elementos cognitivos (visto que a nomeação é inerentemente humana) que direcionaram a escolha de um nome para um determinado lugar. A combinação de tais elementos abrange traços históricos, culturais, sociais e ambientais recortados pelo denominador no ato de nomeação. Divide-se em dois campos: a antroponímia, que estuda nomes próprios em geral e a toponímia, que estuda os nomes de lugar. Aguiar (2018) afirma que

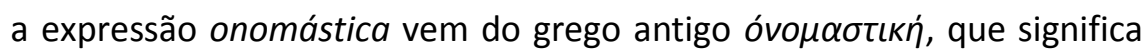
'ato de nomear, dar nomes'. O seu estudo começa no século XIX, quando se ocupa em analisar nomes próprios, considerando suas origens e formas de nomear (AGUIAR, 2018, p. 85). 


\title{
1.2 Toponínia
}

A Toponímia ou Toponomástica, como uma subárea da Onomástica, direciona seus estudos de forma interdisciplinar e abrange conhecimentos de outras áreas, como a História, Geografia, Antropologia, entre outras.

\begin{abstract}
Sabe-se que a toponímia - e nos foi possível enfatizar essa orientação em várias oportunidades anteriores - é a disciplina que caminha ao lado da história, servindo-se de seus dados para dar legitimidade a topônimos de um determinado contexto regional, inteirando-se de sua origem para estabelecer as causas motivadoras, num espaço e tempo preciso, procurando relacionar um nome ao outro, de modo que, da distribuição conjunta, se infira um modelo onomástico dominante ou vários modelos simultâneos (DICK, 1992, p. 12).
\end{abstract}

Ainda que o termo "Toponímia" seja mais comumente empregado para se referir ao estudo dos designativos de lugares, Cabrera (2002) diferencia "Toponímia" e “Toponomástica". Para Cabrera (2003), a toponímia é o conjunto de nomes de lugar, mas a disciplina que os estuda designa-se Toponomástica. Pocklington (s/d) compartilha dessa diferenciação: o termo "toponímia" designa um conjunto de topônimos, um grupo de nomes de lugar que têm algo em comum. Assim, os nomes de lugares de uma determinada região comporiam a toponímia dessa região, enquanto o estudo científico da toponímia seria identificado como Toponomástica.

Para Seabra (2006), o fato de se referir tanto à Toponomástica quanto à Antroponomástica, como Toponímia e Antroponímia, respectivamente, indicam uma relação de inclusão na Onomástica, já que ambas se encontram no onoma, em uma área de intersecção. Convém reafirmar, no entanto, que devido a essa relação de inclusão e 
por esses termos serem mais usados, este trabalho mantém os termos "toponímia e antroponímia”.

O processo de nomeação de lugares se diferencia da denominação de objetos do mundo em geral, já que um signo toponímico carrega certa motivação que se vincula aos fatores que permearam o ato de nomeação. Assim, mesmo que a memória desses elementos tenha se perdido, é necessário considerá-los como fatores que resultaram na escolha do topônimo - o que, de certa forma, faz estabelecer o elo entre o nomeador e o lugar nomeado.

Assim, a toponímia constitui importante área do conhecimento humano capaz de revelar características do ambiente físico e de aspectos da cultura, da sociedade, da história e da geografia dos aglomerados humanos inclusive estabelecendo vínculos teórico metodológicos com essas áreas (DAVID; SIQUEIRA, 2014, p. 123).

Este trabalho se norteia pelo aporte teórico da toponímia, mas irá buscar suporte também na antroponímia, para identificar a relação dos nomes das praças através das relações das relações línguo-culturais, pois cada nomeação tem em seu âmbito aspectos da sociedade que a denominou.

\subsection{Antroponímia}

A antroponímia, como sub-ramo da Onomástica, é o estudo dos nomes próprios atribuídos a seres humanos, o qual se vale de fontes oficiais, como a documentação de cartórios de registro civil, ou de arquivos de paróquias, tais como certidões de batismo. Também pode utilizar listas telefônicas para se embasar nas fontes da pesquisa, mas as 
coletas desses dados não contribuem com a história da língua e da cultura da sociedade que a utiliza. Para Dias (2018), é possível analisar, por meio da organização dos sistemas de denominação do grupo social, uma relação do nome com o meio social, e o nome e seu referente.

A partir do momento em que o vínculo entre objeto e seu nome pode ser observado, é possível reconhecer os elementos que estão na base da denominação recuperados, quando possível, por elementos linguísticos, semânticos, morfológicos e etimológicos. Muitos topônimos são originalmente antropônimos. São assim categorizados, segundo Dick (1990), como antropotopônimos, nomes próprios de pessoas que se tornam designativos de lugares.

\section{Metodologia}

A metodologia consiste em uma combinação de leituras documentais e de investigação de campo; vincula-se, assim, à indução. O percurso apresentado por Dick (1990) desenvolve-se por meio de um plano onomasiológico de investigação. Em outros termos, mediante um conceito genérico, se identificam as variáveis possíveis das fontes consultadas. Nos registros municipais, constam os nomes atuais e os nomes anteriores (quando houve mudanças) dos lugares de toda região municipal. Estes constituem as fontes primárias desta pesquisa.

Como pode haver disparidades entre tais documentos e o nome espontâneo, recorre-se às fontes locais, isto é, ao lugar propriamente dito, onde constam placas com os devidos nomes. 
Em termos linguísticos, o estudo se atém ao levantamento da origem dos topônimos, à estrutura gramatical e à semântica. Segundo Dick (1990), esse procedimento permite também, de forma sincrônica, que se busquem outras modalidades de apreensão do objeto de estudo, descrevendo ou recuperando o continuum denominativo daquela nomenclatura.

O método indutivo possibilita a elaboração de hipóteses de trabalho, construídas ao longo das descrições onomásticas. Confirmadas, elas servem de subsídio para comprovar as hipóteses levantadas acerca dos topônimos como índice para se compreender questões sociais, históricas, culturais dos lugares em questão.

\section{Piracanjuba: breve histórico}

A história de Piracanjuba começa a se desenhar no período conhecido como Século do Ouro no estado de Goiás. Para Boaventura (2007, p. 26), “os bandeirantes foram os primeiros responsáveis pela maioria dos assentamentos goianos". O povoamento foi iniciado por Padre Marinho, que procurava estabelecer relações comerciais entre os estados de Minas Gerais, São Paulo e Goiás, conforme dados do IBGE.

Devido a uma elevação às margens de um córrego, passou então a ser local propício para pouso dos que por ali passavam em busca do ouro. Em razão do grande movimento, ali se instalaram os primeiros moradores, se tornando conhecido naquela época como Pouso Alto. Segundo Pacífico Filho (2016, p. 56), "o pouso de tropas foi o elemento mais significativo do povoamento de Pouso Alto, que não se fixaria sem a existência do patrimônio leigo, da comercialização no engenho e o fluxo de comerciantes e transeuntes". Com a construção da Capela de Nossa Senhora D’Abadia, levantada por 
Guarda-mor Francisco José Pinheiro, no ano de 1831 o lugarejo se efetivou. No ano de 1833, Pouso Alto foi instaurado povoado, sobre as classificações das formações urbanas. Pacífico Filho (2016, p. 33) afirma que "os núcleos que possuíam até quarenta e nove casas eram os lugarejos; entre cinquenta e noventa e nove casas, arraiais; e com cem ou mais casas, povoados".

No ano de 1855, Pouso Alto foi elevado à categoria de Distrito. A denominação de Vila veio em 2 de agosto de 1869. Devido à sua localização próxima à capela e à sua fama de bom lugar para pouso, foi denominada como Nossa Senhora da Abadia do Pouso Alto, pela Resolução Provincial n 428. De Pouso Alto, para o lendário nome Piracanjuba, em 18 de novembro de 1886, imposto pela Lei $\mathrm{n}$ - 786. Retorna a chamar-se Pouso Alto no ano de 1907; oficializada como nome de Piracanjuba no ano de 1943.

O nome da cidade é um topônimo de origem indígena, "do tupi pirá-acan-yuba 'peixe de cabeça amarela ou dourada'” (DAVID; SIQUEIRA, 2014, p. 129), e está relacionado a uma lenda indígena dos tempos do ciclo do ouro: duas tribos indígenas em busca do seu sustento chegaram a uma região localizada entre o rio Meia Ponte e outro canal sem designação. As disputas pelo território fizeram com que as tribos se tornassem inimigos mortais, mas um jovem cacique da tribo dos Piracans apaixonou-se por Jubara, filha do cacique da tribo inimiga. Devido às rivalidades, não puderam viver o amor proibido; sendo assim, os jovens apaixonados atiraram-se juntos no rio, e se afogaram. Depois da tragédia, nas águas do rio Meio Ponte, apareceu no rio uma espécie de peixe que nunca tinha sido visto. Os índios relacionaram o aparecimento do peixe à morte dos jovens apaixonados. Portanto, o rio e o peixe passaram a ser conhecidos como "Piracanjuba", em referência aos jovens índios e a sua triste história. 


\section{Resultados}

Este trabalho tem como foco de estudo duas praças do município de Piracanjuba, cujos nomes são descritos de forma a ressaltar a dupla designação referendada pelas homenagens que aparecem em placas nas referidas praças. Ambos os lugares têm seus nomes oficiais, marcados nas placas indicativas, mas trazem também várias placas homenageando personagens que se destacaram em Piracanjuba, de acordo com o olhar do falante.

Para Siqueira (2015), a escolha de um nome para um dado lugar pode parecer, à primeira vista, uma ação simples, mas não é bem assim. Segundo Siqueira (2015, p. 17), “[...] a nomeação envolve uma série de aspectos que precisam ser verificados para que se possa então pensar em análises linguísticas mais adequadas ao estudo e à categorização da toponímia [...]". Isso também pode ser levado em conta quando se trata de uma mudança de nomes (mudança toponímica), mesmo que esta não se dê em âmbito oficial, apenas como forma espontânea de se referir a um determinado lugar.

Siqueira reitera que tanto a nomeação dos lugares como a mudança toponímica

seguem procedimentos que têm origem em fatos históricos, sociais, culturais e ambientais ou ainda se finca em motivações cuja face cognitiva reflete-se em descrições metafóricas ou metonímicas para escolha do nome do lugar a ser designado (SIQUEIRA, 2015, p. 18).

Assim também se dá quando surge um nome espontâneo em concorrência com o topônimo oficial.

Como o nome espontâneo surge naturalmente, é possível antevê-lo como a representação dos elementos mais salientes do lugar, que são recortados pelo 
denominador em face das características que lhe são mais relevantes ressaltar em termos culturais e históricos.

São manifestações que, segundo Lakoff (1986, apud SIQUEIRA, 2015, p. 19-20), baseiam-se praticamente "em relações espaciais, temporais e ambientais, muitas vezes tendo o corpo humano (o organismo) como referência (ou índice)".

Para Lakoff e Johnson (1999),

as concepções que se têm do mundo são baseadas em experiências concretas e são, em grande parte, definidas por suas características inerentes e por regras contextuais mediadas por metáforas. 0 estudo da categorização nominal evidencia grupos de propriedades inerentes a essas categorias, ou seja, mostra-se útil para compreender a natureza de designações diversas (LAKOFF; JOHNSON, 1999 apud SIQUEIRA, 2015, p. 19-20).

O nomeador categoriza a realidade porque a realidade ou aspectos dela se projetam na mente deles. Nesse sentido, semantizam (ou ressemantizam) o significado conforme a imagem que extraem da realidade circundante, mediante um recorte linguístico.

Espera-se que este estudo possa trazer mais clareza na análise das designações toponímicas que se dão de forma espontânea, pois remetem aos elementos mais salientes desses lugares culturais.

\subsection{Praça Guarda-Mor Francisco José Pinheiro, ou Praça do Relógio}

A Praça Guarda-Mor Francisco José Pinheiro recebeu esse nome como forma de reconhecimento da grande influência que Francisco José Pinheiro teve na emancipação 
de Piracanjuba, lugar em que a fé católica era mais influente. Assim, como o Guarda-Mor tinha bastante influência tanto junto à igreja quanto ao governo, foi homenageado dando nome à praça. É um antropotopônimo, isto é, nomes próprios de pessoas que passam a designar também um determinado lugar, um espaço antromorfizado, pois, pelo ato de nomeação, torna-se referencial, indica aquilo que nomeia.

Ainda pode ser classificado, de acordo com a taxionomia proposta por Dick (1990), como um axiotopônimo, um título agregado a um nome próprio. São topônimos que têm em sua composição (morfossintática) designativos relativos aos títulos e dignidades que acompanham nomes próprios individuais. São lugares culturais, ou seja, lugares transformados pela ação do homem, logo trazem traços específicos da cultura que o criou. Pelo termo linguístico que o designa, é possível conhecer e reconhecer tais traços. Em relação aos antropotopônimos, pode-se dizer que revelam um dado momento da história do lugar nomeado, pois o nomeador deu o nome ao lugar por reconhecer o mérito do homenageado, é relativo a nomes individuais.

Essa praça se localiza no setor central de Piracanjuba. Entretanto, em momentos posteriores da história do lugar, outros "elementos" culturais foram inseridos na praça e estes captaram a atenção do falante. Nessa praça foi inserido um relógio, doação do Ministério da Indústria da China em atenção a um suposto "vínculo de amizade entre China e o município de Piracanjuba".

O Relógio é uma peça em estilo "Big Ben", que informa as horas com soantes badaladas. Assim, a praça passa, com o tempo, a ser conhecida como a "Praça do Relógio". O relógio passou a ser motivo de orgulho e é usado como ponto de referência dos moradores. 
Nessa praça, também foi erguido um monumento em homenagem aos excombatentes da cidade que foram à Europa lutar na Segunda Guerra Mundial. São duas placas em que se homenageiam os "pracinhas" piracanjubenses. Uma delas é uma homenagem póstuma àqueles que tiveram sua vida ceifada pela grande guerra; a outra homenageia aos que combateram e conseguiram voltar ao país. Entretanto, é o Relógio que, de alguma forma, deu motivação à nomeação espontânea. Um processo metonímico, uma parte do lugar, nomeia o todo.

Assim: o topônimo Praça do Relógio é formado pelo termo genérico "praça", que, segundo Cunha (1986), é um

[...] lugar público, cercado de edifícios, largo, mercado, feira. XIII, praza, XIV| Do latim vulgar *plăttěa, de plătěa. No português medieval, já se documentam a locução adverbial em praça 'em público' [...]; + nome "relógio"; da tradução do nome latino Horologium" (CUNHA, 1986, p. 627).

Segundo Machado (2003, p. 1.253), há alguns topônimos portugueses que têm "relógio" na composição do topônimo: “em Alenquer (Casais"ii do Relógio). Azambuja (Casal do Relógio) Cascais, Oeiras, Porto (rua), Sintra (Quinta do Relógio). V. N. de Gaia. Do s.m. relógio". Cunha (1998) ratifica a origem de "relógio" do latim horologium-ii, derivado do grego horológion [...]".

\subsection{Praça Dimas Costa, ou Praça da Matriz}

A Praça Dimas Costa situa-se defronte da igreja matriz "Nossa Senhora da Abadia" em Piracanjuba. Segundo Pacífico Filho (2016, p. 85), “posteriormente, sem qualquer 
controle do poder público, o largo veio a se tornar a Praça Dimas Costa de Piracanjuba". O nome da praça faz referência a um jovem membro da tradicional família "Costa", a qual tinha influências econômicas e posses de fazendas ao redor da cidade. Dimas Costa foi assassinado ainda jovem; a população, homenageando à família, deu à praça o nome de seu filho, cuja vida foi ceifada de forma cruel.

Entretanto, a praça homenageia também o poeta Leo Lynce (pseudônimo de Cyllenêo Marques de Araújo Valle), nascido em 1884 em Piracanjuba. Era jornalista, advogado, fazendeiro, juiz de direito, entre outras profissões, que exerceu no decorrer de sua vida até seu falecimento, no ano de 1954. Foi percursor do modernismo literário em Goiás com a publicação de seu livro Ontem, de 1928. Segundo Teles (1964, p. 125), "foi através de Leo Lynce que os goianos tomaram contato, pela primeira vez, com as grandes contribuições estéticas do Modernismo brasileiro." Adotava em seus poemas traços nacionalistas, e trazia em seus versos inovações na linguagem; empregava em seus recursos a expressividade. Assim, afirma Teles (1964, p. 125): "referimo-nos à adoção de concepções nacionalistas, de reformulações temáticas e estéticas, de inovações através de uma linguagem valorizada nos seus múltiplos recursos de expressividade". Representa o maior vulto artístico da história piracanjubense.

É um antropotopônimo, um topônimo de natureza antropocultural, é um nome próprio de pessoas que passa a nomear também um determinado lugar, antromorfizado pela designação que recebe, pois, pelo ato de nomeação, torna-se referencial, aponta para o lugar que nomeia.

A nomeação da praça carrega traços históricos e culturais de determinada época de quem a nomeou, traz referencias à história porque recorta traços do que são mais salientes de acordo com a visão de mundo do nomeador. A população piracanjubense 
chama a Praça Dimas Costa de "Praça da Matriz", por ser a referência mais adequada àqueles que precisam se referir a ela, por ter a igreja como objeto de referência. Tem-se então: termo genérico "praça" + matriz do lexema "mãe", conforme Cunha (1986, p. 507), "mátr. io, -iz, -ona, -onal $\rightarrow$ mãe". Segundo Machado (2003), trata-se de um topônimo “Portel (Hora da matriz). Do f.m. matriz <<manacial, mãe-de-água >>”.

\section{Considerações finais}

Ao nomear os espaços antes naturais, depois transformados pela ação do homem, o nomeador, que pode ser individual ou coletivo, o faz de um ponto panorâmico da paisagem, que se faz cultural, do um ponto recortado de onde pode vê-la em sua plenitude. No entanto, por razões de ordem cognitiva, devido ao conhecimento e à visão de mundo desenvolvido ao longo de anos por sua cultura e que, consequentemente, o impregnam, faz um recorte e escolhe uma característica, um elemento específico do lugar, que, na sua visão de mundo, possa representar todo o espaço recém-nomeado. 0 processo espontâneo de nomeação da Praça do Relógio se deu dessa maneira: o objeto, inserido no lugar que já estava construído e nomeado, capta a atenção do nomeador, tornando-se a designação e referência para o lugar.

Em relação à Praça da Matriz, a referência não é ao poeta nascido na cidade, e nem ao jovem de família influente, mas a associação da praça com a igreja matriz, também lugar simbólico do ponto de vista do falante.

Assim, o estudo do signo linguístico em função toponímica pode revelar elementos importantes dos valores axiológicos da história de um lugar. Especialmente quando se trata de topônimos espontâneos, já que estes refletem as especificidades do 
lugar recortadas pelos falantes em suas interações com outros falantes e com o lugar em que vivem, o que remete a inúmeros processos motivacionais que culminam com a escolha de um nome específico para um determinado lugar, seja uma rua, uma praça, uma cidade, mesmo que tal escolha não coincida com o nome cartorial.

O estudo de nomes espontâneos suscita a ideia de que a maioria dos topônimos advém de maneira espontânea da percepção e da inter-relação do falante com o lugar nomeado, ainda que entrem em concorrência com os topônimos ditos oficiais, que são resultados de atos fundacionais, de escolhas pensadas e marcadas por motivações de diversas ordens em atos oficiais, normalmente registrados em documentos.

Os topônimos são como catalisadores tanto de fatores linguísticos, como os religiosos, históricos e geográficos, porque preservam elementos apagados pela história. Estes constituem, quase sempre, os fatores que motivaram a escolha de determinado nome para um dado lugar.

Segundo Dick (1990), o estudo dos topônimos só pode ser feito mediante a compreensão desses fatores históricos e, por conseguinte, do contexto que the deu origem e que o justifica. Assim, nem sempre é necessário situar o objeto num plano de representação, uma vez que a fixação das bases lexicais para designar lugares dispensa essa representação. 0 processo de simbolização das formas linguísticas transforma o nome em lugares existenciais. A configuração de um determinado lugar só ocorre depois de nomeado, espontaneamente ou não.

\section{Referências}


AGUIAR, Maria Suelí de. Hagiônimos em Goiás. In: AGUIAR, Maria Suelí; CASTRO, Maria Célia Dias de; DIAS, Ana Lourdes Cardoso (orgs.). Onomástica e identidade do homem em seu meio. Goiânia: Editora Imprensa Universitária, 2018.

BIDERMAN, Maria Tereza Camargo. Dimensões da palavra. Filologia e Linguística Portuguesa, Araraquara, n. 2, p. 81-118, 1998.

BOAVENTURA, Deusa Maria Rodrigues. Urbanização em Goiás no século XVIII. 2007. 280p. Tese (Doutorado em Arquitetura e Urbanismo) - Faculdade de Arquitetura e Urbanismo, Universidade de São Paulo. São Paulo, 2007. Disponível em:

<http://www.teses.usp.br/teses/disponiveis/16/16133/tde-13052010-090028/ptbr.php>. Acesso em: 28 ago. 2018.

CABRERA, Genoveva Torres. Sobre toponomástica. Philologica canarie. Las Palmas de Gran Canarias: REBIUN, n. 8-9, p. 191-206, 2002-2003. Disponível em:

<http://www.canatlantico.ulpgc.es/pdf/8/7/Sobre_toponomastica.pdf>. Acesso em: 16 ago. 2018.

CUNHA, Antônio Geraldo. Dicionário etimológico. 2. ed. Rio de Janeiro: Nova Fronteira, 1986.

DIAS, Ana Lourdes Cardoso. Antropônimos: Interação linguística e sociolcultural. In: AGUIAR, Maria Suelí; CASTRO, Maria Célia Dias de; DIAS, Ana Lourdes Cardoso (orgs.). Onomástica e identidade do homem em seu meio. Goiânia: Editora Imprensa Universitária, 2018. p. 237-274.

DICK, Maria Vicentina de Paula do Amaral. A motivação toponímica e a realidade brasileira. São Paulo: Edições Arquivo do Estado de São Paulo, 1990.

. Toponímia e antroponímia no Brasil: coletânea de estudos. São Paulo: FFL/USP, 1992.

IBGE. IBGE | Brasil em Síntese | Goiás | Piracanjuba | Panorama. Disponível em: <https://cidades.ibge.gov.br/brasil/go/piracanjuba/panorama>. Acesso em: 13 mai. 2018. IBGE. IBGE | Piracanjuba. Disponível em: <https://biblioteca.ibge.gov.br/visualizacao/periodicos/112/col_mono_ns_n79_piracanju ba>. Acesso em: 14 set. 2018.

MACHADO, José Pedro. Dicionário onomástico etimológico da língua portuguesa. Lisboa: Livros Horizonte, 2003. 
PACÍFICO FILHO, Valdecir José. A repartição do chão e as condições administrativas e legais para o sugimento de Piracanjuba (1831/1886). 2016. 125f. Dissertação (Mestrado em História) - Pontifícia Universidade Católica de Goiás, Goiânia, 2016.

POCKLINGTON, Robert. Introducción a la Toponomástica, s/d. Disponível em: <http://www.academia.edu/21713377/INTRODUCCI\%C3\%93N_A_LA_TOPONOM\%C3\%81 STICA_-_1._ASPECTOS_UNIVERSALES_DE_LA_TOPONIMIA>. Acesso em: 16 ago. de 2018.

SEABRA, Maria Cândida. Referência e onomástica, 2006. Disponível em: <http://filologia.org.br/ileel/default.html> Acesso em: 16 de ago. de 2018.

SIQUEIRA, Kênia Mara de Freitas; DAVID, Nismária Alves. Topônimos de origem indígena: o papel do tupi na nomeação dos lugares goianos. FRONTEIRAS: Journal of Social, Technological and Environmental Science. Anápolis: Uni-Anhanguera, v. 3, p. 119-131, julho 2014.

Do vai-vem passando Entre Rios até Ipameri (GO): considerações acerca da mudança toponímica. In: COUTO, Elza Kioko Nakayama Nenoki do; ALBUQUERQUE, Davi Borges (orgs.). Linguística ecossistêmica e análise do discurso ecológica: teoria e aplicações. Brasília: Thesaurus, 2015. p. 12-29.

- Inter-relação língua e cultura: breves considerações sobre o conjunto hierotoponímico de Goiás. In: AGUIAR, Maria Suelí; CASTRO, Maria Célia Dias de; DIAS, Ana Lourdes Cardoso (orgs.). Onomástica e a identidade do homem. Goiânia: Editora Imprensa Universitária, 2018. p. 67-94.

TELES, Gilberto Mendonça. A poesia em Goiás. Goiânia: Ed. UFG, 1964.

Recebido em 15 de setembro de 2018.

Aceite em 24 de novembro de 2018.

\footnotetext{
'Não foi encontrado, até o momento, um documento de doação do relógio.

ii Em Machado (2003, p. 365), “topônimo frequente em Portugal e na Galiza. Do s.m. casal. Casale em 1094; Kasalem em 1117 [...]".
} 